\title{
Envisioning innovative technology of three dimensional virtual worlds (3D VWs) for continuing professional development (CPD) programs
}

\author{
ImadEldin Mohamed Nour ${ }^{1}$, Asim Ahmed Elnour ${ }^{2,3 *}$, Wala Hilal Hussein Hilal $^{4}$, Montaha \\ Mustafa Yousef ${ }^{5}$ \\ ${ }^{1}$ Ministry of Health Directorate General of Pharmaceutical Affairs and Drug Control, Sultanate of Oman. \\ ${ }^{2}$ Faculty-Pharmacy, Fatima College of Health Sciences, UAE. \\ ${ }^{3}$ Adjunct Associate Professor, Monash University, Australia. \\ ${ }^{4}$ Fifth year student, Pharmacy College, Fatima College of Health Sciences, UAE. \\ ${ }^{5}$ Third year student, Pharmacy College, Fatima College of Health Sciences, UAE
}

Received: August 31, 2016; Accepted: September 1, 2016; Published: September 15, 2016

*Corresponding author: Asim Ahmed Elnour, Faculty-Pharmacy, Fatima College of Health Sciences, UAE and Adjunct Associate Professor, Monash University, Australia, Tel: +971525437665,+96899791465; Email: asim.ahmed@hfchs.ac.ae; imad.nour@moh.gov.om

\section{Historical perspectives}

Continuing Professional Development (CPD) can be defined as the holistic commitment of professionals towards the enhancement of personal skills, competencies and proficiency throughout their careers. It is a combination of approaches, ideas, tools and techniques that help to manage learning process, development and growth. It guarantees that knowledge stay relevant and up to date; however, it should be engaging and in fun too. "Tell me and I'll forget; show me and I may remember; involve me and I'll understand" [1] - Chinese proverb.

The concept of CPD for healthcare professionalshas emerged out of an experiential learning model that encompasses changing one's actions as a result of reflecting about new experiences ${ }^{2}$.

This was backdated to the late 1960s and early 1970s, where it became apparent that undergraduate education did not entirely prepare an individual for working life or imply lifelong competence [3]. Dubin [4] proposed the half-life concept in order to estimate the extent of becoming out of date with new technology and knowledge. A half-life of 5 years was applied to medicine and engineering.Australia, New Zealand, United Kingdom and Canada adopted a form of CPD in the 1990s, in response to a growing awareness of diminished quality care and learner engagement in healthcare [2, 5]. Similar to most other professions, healthcare providers need some form of continuous learning (formal and informal) to remain up to date, relevant and beneficial to their patients.

\section{Types of CPD}

Types of CPD learning vary significantly, depending on the requirements for the intended business, or if you're learning as an individual.CPD structured / active learning involves interactive and participation-based study. It is typically proactive and can include attending a training course, conference, workshop, seminar, lecture, e-learning course or CPD certified event. CPD active learning also applies to when professionals take career orientated exams and assessments (the study and revision would be considered self-directed learning).

Reflective learning involves no participant-based interaction, as this form of CPD is much more passive and one directional. Examples of this include reading relevant news articles, podcasts, case studies and industry updates. Some informal meetings can be applicable to CPD reflective learning, but the learning objectives of these meetings must be clearly stated with learning outcomes in an individual's overall CPD plan.

Self-directed learning involves all unaccompanied CPD activities. It covers the reading of documents, articles, relevant news and publications; either in print or online. Reading relevant publications, books by leading experts, industry journals and trade magazines are all types of self-directed CPD. One may include industry-specific news feeds or research into relevant fields.

\section{The new emerging CPD technology}

The current evidence support the effectiveness of technologyenabled CPDsuch as e-Learning courses or short learning points, Electronic data collection and analysis, Technology-enabled simulation, e-Mentoringand Social networking.

In recent times, the three Dimensional Virtual Worlds (3D VWs) are very attractive for education and learning as they provide realistic three-dimensional environments that resemble the real scenario, offer engaging, interactive and immersive experiences, and create new prospects related to learning and teaching [6]. This 3D Virtual can be in form of classroom simulation taking into account designconsiderations formulated by educational 
activities that derive from the instructional strategy of "Synectics - Making the strange familiar" [7]. Another example is 3D Virtual Classroom Simulation using SLOODLE (Simulation Linked Object Oriented Dynamic Learning Environment) [8].

\section{Conclusions}

In an ever advancing technology, CPD strategies for medical profession need to get informed about the 3D VWs technology, trained, ease of access, flexibly, involved and practice the use of this innovative solutions to their advanced CPD programs.

\section{Conflict of interest}

There is no any conflict of interest

\section{References}

1. Think-Exist.com. Finding Quotes was Never This Easy.
2. Rouse MJ. Continuing professional development in pharmacy. Am J Health-Syst Pharm 2004;61:2069-2076.

3. Payne CB. Continuing professional postgraduate education: overview and issues. NZ J Adult learn. 1993;21:113-28.

4. Dubin SS. Obselesence or lifelong education: a choice for the professional. Am Psychol. 1972;27(5):496-498.

5. Institute of Medicine. Redesigning continuing education in the health professions. Washington DC. National Academies Press. 2010.

6. Esteves M, Fonseca B, Morgado L and Martins P. Using Second Life for Problem Based Learning in Computer Science Programming. Journal of Virtual Worlds Research, 2009;2(1):4-25.

7. Joyce RB, Weil M and Calhoun E. Models of Teaching 6th Edition, Allynand Bacon. 2000.

8. Livingstone D. Online Learning In Virtual Environments with SLOODLE, Computing and Information Systems Technical Reports, No 50. ISSN 1461-6122. 2009. 